\title{
O TRABALHO DO PROFESSOR E AS PRESCRIÇÕES DO DOMÍNIO DA LEITURA NAS AE EM PORTUGAL
}

\author{
Sandra Patrícia Ataíde Ferreira \\ Universidade Federal de Pernambuco \\ Departamento de Psicologia e Orientação Educacionais \\ tandaa@terra.com.br \\ Audria Albuquerque Leal \\ Centro de Linguística da Universidade Nova de Lisboa \\ Fundação para Ciência e Tecnologia \\ audrialeal@fcsh.unl.pt
}

Fecha de Recepción: 2 Abril 2019

Fecha de Admisión: 30 Abril 2019

\section{RESUMO}

Objetiva-se refletir sobre as prescrições do ensino e aprendizagem da leitura materializadas nas Aprendizagens Essenciais (AE) referentes ao $2^{\circ}$ Ano do $1^{\circ}$ Ciclo do Sistema de Ensino de Portugal. As AE são definidas como Denominador Curricular Comum para todos os alunos do território Português e estão em convergência com o Perfil dos Alunos à Saída da Escolaridade Obrigatória. Parte-se do pressuposto que a leitura é uma atividade complexa que requer o ensino de estratégias cognitivas e discursivas que permitam 0 diálogo do leitor com 0 autor a partir de um posicionamento responsivo. Compreende-se, também, que o trabalho do professor se realiza como uma atividade coletiva, que é dirigida aos alunos e a outros sujeitos da comunidade escolar. 0 professor é concebido como um sujeito ativo que redefine para si mesmo as tarefas que the são prescritas e define aquelas que irá prescrever para os alunos. Nesta apresentação, reflete-se sobre a dimensão das prescrições para entender o trabalho do professor no âmbito da leitura por meio do método indireto, conforme a perspectiva vigotskiana. Para alcançar 0 objetivo, pretende-se: (i) apresentar 0 documento; (ii) discutir o seu contexto de produção; (iii) refletir sobre o status da leitura para a formação do sujeito.

Palavras-chave: trabalho do professor; aprendizagens essenciais; leitura; ensino; aprendizagem

\section{ABSTRACT}

Teacher's work and the requirements of the field of reading in AE in Portugal. This work aims to reflect on the teaching and learning requirements of reading materialized in the Essential Learning (EL) referring to 2st Year of the 1st Cycle of the Portuguese Teaching System. The EL are defined as 


\section{O TRABALHO DO PROFESSOR E AS PRESCRIÇÕES DO DOMÍNIO DA LEITURA NAS AE EM PORTUGAL}

a Common Curricular Denominator for all students in Portuguese territory and are in convergence with the Profile of the Students at Exit of Compulsory Schooling. It is assumed that reading is a complex activity that requires teaching of cognitive and discursive strategies that allow the reader's dialogue with the author from a responsive positioning. It is also understood that teacher s work is carried out as a collective activity, which is directed to students and other subjects of the school community. The teacher is conceived as an active subject who redefines tasks that are prescribed to him and defines the ones he will prescribe for the students. In this presentation, we reflect on the dimension of prescriptions to understand teacher $s$ work in the scope of reading through the indirect method, according to the vigotskian perspective. To achieve the objective, it is intended: (i) to present the document; (ii) discuss their production context; (iii) reflect on the reading status for subject's formation.

Keywords: teacher's work; essential learning; reading; teaching; learning

\section{INTRODUÇÃO}

Neste trabalho, em consonância com a perspectiva de Amigues (2004), defende-se o pressuposto de que o trabalho do professor é uma atividade de concepção e de organização voltado para a atividade dos alunos e para ele mesmo através de meios de trabalho. Os meios (ferramentas e recursos) são mediados pelo professor, reconstruídos e co construídos pela ação coletiva em sala de aula e pelo engajamento dialógico dos alunos, através do questionamento didático realizado por esse profissional. Pelo engajamento, pode haver a apropriação e transformação da ferramenta em instrumento de pensamento, abrindo novas possibilidade de ação para os alunos, porque 0 instrumento é um meio de autorregulação e de autocontrole dos próprios comportamentos dos sujeitos na relação com 0 objeto de conhecimento que passa a ser internalizado (Friedrich, 2012, Vigotski, 1991).

No que se refere ao professor de línguas, entende-se que ele tem como tarefa de ofício ensinar o estudante a refletir sobre a língua para além do seu uso (Marcuschi, 2008) e, especificamente, promover 0 ensino e a aprendizagem dos eixos de produção textual, análise linguística, oralidade e leitura. Então, para a compreensão das regras de ofício do professor sobre 0 ensino e a aprendizagem da leitura, assume-se a noção de que essa atividade está para além da decodificação do sistema de escrita alfabética, entendendo a como produção de sentido caracterizada pelas relações dialógicas entre o leitor e 0 autor do texto em contexto específico (Bakhtin, 2003). Além disso, defende-se que a leitura não é uma atividade dada a priori, mas ensinada e aprendida, sendo a escola um contexto privilegiado dessa aprendizagem. Também se acredita que a capacidade de leitura (re)configura-se ao longo do desenvolvimento do sujeito (Ferreira, Lima, \& Gonçalves, 2011) a partir de diferentes experiências e da inserção do leitor em diferentes contextos, necessitando da mediação de outros (pais, professores) para que essa atividade se realize e se atualize. Por outro lado, entende-se que esses conhecimentos precisam ser objeto de reflexão em programas de formação de professores, visto que têm implicações sobre a atividade docente de ensino e aprendizagem da leitura (Suárez \& Jiménez, 2014), em especial, quando esta é tomada como processo dialógico.

No que se refere à análise do trabalho do professor, o ISD propõe que se realize a articulação entre tarefa e atividade, bem como as relações de tensão entre trabalho prescrito e trabalho realizado por meio das relações entre ação e atividade. (Bronckart, 2004/2006). Neste artigo, privilegia-se a dimensão do trabalho prescrito, tendo-se a compreensão de que o método indireto proposto por Vigotski (1926/2004), que fundamenta a perspectiva do ISD, é fundamental para apreender a atividade e a ação do trabalho do professor porque permite interpretar não apenas o realizável, mas também o possível, ou seja, o que não foi realizado, mas poderia sê-lo a fim de realizar a ação proposta (Friedrich, 2012). Isto, a partir da interpretação e da reconstrução de traços presentes em docu- 
mentos, em testemunhos e em testemunhos de testemunhos de maneira indireta, mas objetiva, como é próprio dos métodos históricos e das ciências humanas, segundo Vigotski (1926/2004).

Diante disso, assumem-se os documentos oficiais de políticas públicas educacionais como uma das pistas para interpretar e reconstruir o trabalho desse profissional no que se refere ao ensino $\mathrm{e}$ à aprendizagem da leitura na escola e na sala de aula. Então, ao tomar as Aprendizagens Essenciais (2018) como um traço de reconstrução do trabalho docente, questiona-se: quais as determinações existentes nesse documento sobre 0 ensino da leitura que podem mobilizar as ações do professor na realização de seu trabalho? Assim, objetiva-se refletir sobre as prescrições do ensino e aprendizagem da leitura materializadas nas Aprendizagens Essenciais (AE) referentes ao $2^{\circ}$ Ano do $1^{\circ}$ Ciclo do Sistema de Ensino de Portugal.

Com isso, visa-se trazer contribuições para se (re)pensar o trabalho do professor no âmbito do ensino e aprendizagem da leitura, tendo como foco as políticas públicas educacionais assumidas como um dos mobilizadores da ação docente em sala de aula e, portanto, como um dos elementos que tem implicações sobre a formação de futuros leitores em uma sociedade que cada vez mais enredada em diferentes textos e linguagens.

\section{MÉTODO}

Foi realizada uma análise documental de cunho qualitativo com o objetivo de fazer apreciação das prescrições sobre 0 ensino e a aprendizagem da leitura que regulam as ações dos professores nas Aprendizagem Essenciais (AE) - $2^{\circ}$ ano, $1^{\circ}$ Ciclo da Escola Básica, em Portugal. Para apreender os sentidos revelados por esse documento, assumiu-se o método materialista-dialético da psicologia histórico cultural de Vigotski (1991), privilegiando-se as categorias metodológicas de totalidade, unidade de contrários e historicidade.

Assim, procedeu-se 0 movimento de relação entre 0 todo e as partes das Aprendizagens Essenciais (EA) no confronto com outros documentos que revelam o movimento histórico sobre 0 currículo, o papel do professor e aluno, e, especialmente, sobre o ensino e aprendizagem da leitura, em Portugal, em um devir próprio da dialética

Para tal, além das EA, foram lidos outros documentos oficiais referentes às políticas públicas da educação de Portugal que integram o currículo da Escola Obrigatória, pareceres sobre as AE produzidos por entidades ligadas à educação, bem como documentos com orientações internacionais e com diretrizes europeias. Todos foram lidos na íntegra, mas com o foco nas discussões sobre 0 objeto leitura, notadamente, quando da análise do ensino e da aprendizagem dessa atividade nas $A E$ na interlocução com o Programa e Metas Curriculares de Português do Ensino Básico, que continua a vigorar juntamente com as $\mathrm{AE}$ e a orientar as ações dos professores nesse âmbito do ensino.

\section{RESULTADOS E DISCUSSÃO}

A análise foi organizada de modo a contemplar três secções independentes, mas relacionadas: (i) apresentação das características globais das AE; (ii) discussão sobre o contexto sócio interacional desse documento, com destaque para a sua gênese e o seu desenvolvimento; (ii) interpretação do status do ensino e da aprendizagem da leitura nas $A E$, discutidas a seguir.

\section{Características globais do texto Aprendizagens Essenciais - Português: 1 Ciclo do Ensino Básico}

Aprendizagens Essenciais/Articulação com o Perfil dos Alunos - Português, como é intitulado 0 documento das AE dessa área do currículo, está disponível no portal da Direção-Geral da Educação - República Portuguesa, em arquivo Portable Document Format (pdf), conforme decisão do Despacho n0 8476-A/2018 que determina que as AE sejam "publicitadas na Internet, no sítio da 


\section{O TRABALHO DO PROFESSOR E AS PRESCRIÇÕES DO DOMÍNIO DA LEITURA NAS AE EM PORTUGAL}

Direção-Geral da Educação (DGE) e, sempre que aplicável, no sítio da Agência Nacional para a Qualificação e o Ensino Profissional (ANQEP, I. P.)". 0 documento de cada área/disciplina aparece como hipertexto de um texto principal e introdutório sobre a abrangência e finalidades das $A E$, ao qual se agrega como uma rede de informações em interação.

No que se refere ao 1ํㅡㄹ Ciclo do Ensino Básico, esse documento é constituído de quatro partes, cada uma delas correspondendo a cada um dos quatro anos que compõe esse nível de ensino, a saber: $1^{\circ}$ ano, $2^{\circ}$ ano, $3^{\circ}$ ano e $4^{\circ}$ ano. As $A E$ do $1^{\circ}$, do $2^{\circ}$ e do $4^{\circ}$ ano são compostas de 13 páginas, e as do $3^{\circ}$ ano, de 14 páginas. Assim como os demais documentos das outras diferentes áreas do currículo, as quatro partes que integram as $\mathrm{AE}$ - Português do referido nível de ensino, são constituídas das seguintes partes: (a) Apresentação do racional específico da disciplina (texto breve de introdução); (b) Tradução das dimensões do PA (Perfil do Aluno), nas AE de cada disciplina/ano; (c) Seleção, por ano/área das aprendizagens essenciais da disciplina; (d) Explicitação de ações de ensino associadas aos descritores do Perfil dos Alunos, articuladas com as AE (Roldão, Peralta, \& Martins, 2017, pp.11-12), conforme se observa na reprodução da imagem do template infra, na Figura 1.

Figura 1. Template infra da organização textual das $A E$

Fonte: Roldão, Peralta e Martins, 2017, p. 13-14.

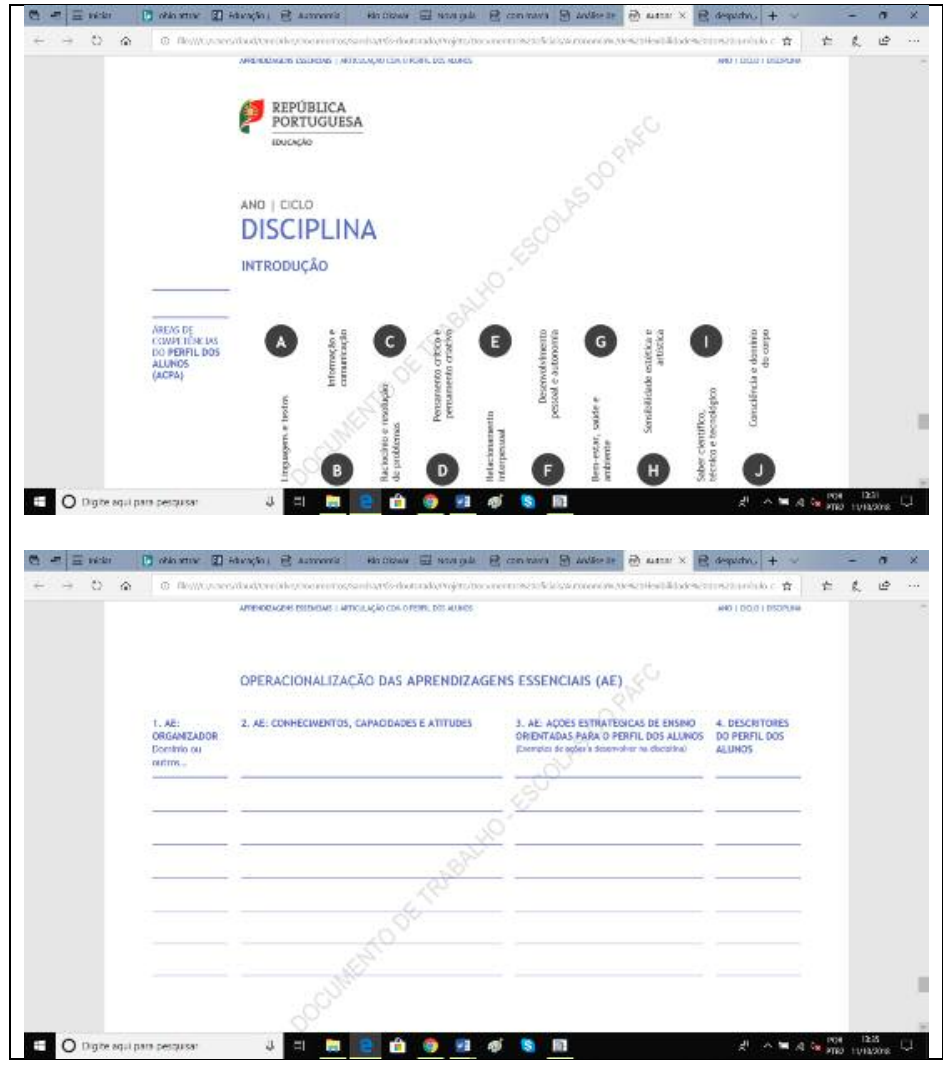


A Introdução, nas quatro partes das AE - Português do 1ํㅡㄹ Ciclo do Ensino Básico, apresenta 0 mesmo conteúdo temático: definição do Português como objeto de conhecimento, explicitação das suas áreas de ensino e aprendizagem, definição dos conceitos-chave relativos à língua/linguagem e explicitação das competências, articuladas com o Perfil dos Alunos, necessárias a desenvolver em cada área: oralidade, leitura, educação literária, escrita/produção textual e análise linguística. A descrição dessas competências varia de acordo com o objetivo da área de Português para cada ano do 1 ํ Ciclo do Ensino Básico e das aprendizagens que devem ser consolidadas e aprofundadas ao longo do ensino obrigatório.

Estruturalmente, o documento das AE apresenta-se sem capa, mas com identidade, já que é emoldurado na margem superior, em cor azul ${ }^{1}$, pelo título, mês e ano de publicação e pelo símbolo da República Portuguesa representado pela bandeira nacional estilizada, possivelmente aludindo a primeira letra do nome do país. Exceto a Introdução, as demais informações são organizadas em diagrama e tabelas, talvez para favorecer a consulta por parte dos professores e demais participantes da escola, e facilitar a realização das ações esperadas para a consecução das competências previstas no Perfil dos Alunos, em cada área do currículo. 0 emissor-enunciador e receptor-destinatário não estão explicitados nesse documento, embora sejam referidos no Despacho $n^{0}$ 8476-A/2018 que homologa as $\mathrm{AE}$.

Esses documentos são nomeados de "orientação curricular" (APRENDIZAGENS, 2018, documento eletrônico) porque, como explicitam Roldão, Peralta e Martins (2017, p.4), pretendem um "formato menos prescritivo e mais orientativo" em uma perspectiva de currículo futuro orientada pelos referentes internacionais, a exemplo da Agenda 2030 (UNESCO, 2017), e que visam a conciliar um currículo comum com a autonomia das escolas para decidir sobre a organização curricular tendo em conta a especificidade dos seus alunos e de seu contexto. Assim, aparentemente apresentam características de um Guia de Orientações Pedagógicas e possivelmente cumprem à função comunicativa de municiar os professores na concretização do previsto no Perfil dos Alunos à Saída da Escolaridade Obrigatória (doravante Perfil dos Alunos) e na realização do conjunto do currículo elaborado e almejado para a efetivação da equidade de direitos dos cidadãos portugueses em formação escolar e para a aprendizagem ao logo da vida.

\section{Contexto sócio interacional de Produção das Aprendizagens Essenciais: gênese e desenvolvi- mento}

As Aprendizagens Essenciais (AE), parte integrante da reorganização curricular do ensino básico e secundário de Portugal, homologadas pelo Despacho n0 8476-A/2018, em 31 de agosto de 2018, são definidas como Denominador Curricular Comum para todos os alunos do território Português, ou seja, como um conjunto comum de conhecimentos, capacidades e atitudes a serem desenvolvidos pelos sujeitos em processo de formação escolar obrigatória (APRENDIZAGENS, 2018, documento eletrônico).

As AE estão em convergência com o Perfil dos Alunos e foram construídas com base nos documentos curriculares existentes ${ }^{2}$, materializando-se como "documentos de orientação curricular base na planificação, realização e avaliação do ensino e da aprendizagem" (APRENDIZAGENS, 2018, documento eletrônico), tendo como objetivo central promover o desenvolvimento das áreas de competências definidas no Perfil do Aluno.

Esses documentos foram elaborados com a coparticipação de diferentes atores do setor educacional em parceria com peritos e outras entidades sociais, configurados simultaneamente como os primeiros emissores-enunciadores/receptores-destinatários da proposta defendida nesses documentos (Machado, 1998), os quais "permitissem uma efetiva flexibilização e gestão curriculares por 


\section{O TRABALHO DO PROFESSOR E AS PRESCRIÇÕES DO DOMÍNIO DA LEITURA NAS AE EM PORTUGAL}

parte das escolas e dos docentes" (DESPACHO n0 8476-A/2018), os receptores-destinatários finais das AE. Isso com o propósito de garantir o ensino de qualidade, a equidade de aprendizagens e a inclusão escolar com foco no desenvolvimento de competências de nível elevado, em uma perspectiva interdisciplinar e articulada de currículo, nos diferentes níveis de ensino.

Enquanto elemento integrante da reorganização curricular, as $A E$ também atendem à necessidade de repensar a questão da extensão do currículo identificada, em especial, por professores, pais, alunos e encarregados da educação e que é avaliada como impeditiva da "[...] consolidação de aprendizagens, do aprofundamento do conhecimento essencial de cada disciplina, do desenvolvimento de competências de nível mais elevado, bem como um obstáculo à inclusão de alunos com necessidades específicas [...]" (DESPACHO n0 8476-A/2018). Por outro lado, o Parecer $n^{0}$ 04/2018 do Conselho das Escolas da República Portuguesas, sobre o Projeto de Decreto-Lei que estabelece o currículo do ensino básico e secundário e os princípios orientadores da avaliação das aprendizagens, hoje Decreto-Lei $n^{055 / 2018}$, nas suas conclusões, adverte que a proposta de reorganização do currículo poderá não alcançar a articulação pretendida. Isto porque prescreve acréscimo de novos componentes curriculares/disciplinas que podem levar à fragmentação do currículo, não atendendo, portanto, ao propósito pretendido de promover as aprendizagens em uma perspectiva articulada de conteúdos de várias disciplinas, com redução desses conteúdos e ganhos qualitativos de solidez no currículo (Roldão, Peralta, \& Martins, 2017).

Relacionada a esse propósito de integração e interdisciplinaridade para garantir 0 aprofundamento das aprendizagens em uma perspectiva horizontal e vertical ao longo da escolaridade obrigatória, está a noção de que as AE "estão ancoradas em uma cultura de escola de autonomia e de trabalho em equipa educativa dos docentes, nomeadamente ao nível do conselho de docentes ou do conselho de turma."(DESPACHO n0 8476-A/2018). Algo, aliás, que prevê a adequação das propostas curriculares aos alunos a depender da realidade de cada escola, criando possibilidades de flexibilidade do currículo, como define o Projeto de Autonomia e Flexibilidade Curricular (DESPACHO $\mathrm{n}^{0}$ 5908/2017), que funcionou em regime de experiência pedagógica em mais de duas centenas de escolas públicas e particulares de Portugal no ano letivo de 2017-2018.

Porém, como é advertido no Parecer n0 11/2018 do CNE, a duração e os poucos dados relativos a essa experiência de flexibilidade curricular impediu uma avaliação fundamentada e ponderada, o que esse Conselho "por várias vezes tem afirmado como fundamental para nortear as opções educativas" (p.07). Por outro lado, essas ideias surgem, dialogam e se concretizam em convergência com 0 que defende também o CNE acerca da necessidade de se estabelecer margens de adaptação do currículo pelas escolas a partir de um currículo comum ou de uma base comum de referência (CNE, Parecer $n^{0}$ 2/2012 citado no CNE, Parecer $n^{0}$ 11/2018).

0 princípio de autonomia e flexibilidade curricular é almejado assumindo-se o professor como o centro do desenvolvimento curricular em integração com alunos e carregados da educação na identificação de opções curriculares em diálogo com as famílias e a comunidade (CNE - Parecer $\mathrm{n}^{0}$ 11/2018). Isto, em uma perspectiva de integração e de participação dos atores da escola com outros setores da sociedade para responder de forma conjunta aos complexos desafios impostos pela sociedade contemporânea e que "superam os processos básicos de resolução de problemas que se atêm estritamente ao planejado" (UNESCO, 2017). Além disso, esse princípio, de acordo com 0 parecer do CNE (Parecer $n^{0}$ 11/2018), mostra-se positivo porque anuncia uma mudança de paradigma curricular em Portugal, tradicionalmente pouco flexível.

Em contraposição, os Pareceres do CNE e do Conselho das Escolas alertam para a incoerência de não se considerar que a opção de flexibilização escolhida pela escola não resulte de aumento de recursos pessoal, material e financeiro, já que esse se mostra como um dos condicionantes para a 
garantia da qualidade das aprendizagens. Qualidade essa necessária ao combate da desigualdade e concretização dos direitos humanos como preconiza a Agenda Global da Educação 2030 para 0 desenvolvimento sustentável (UNESC0, 2017) e que o XXI Governo Constitucional de Portugal, assumindo a educação como alicerce essencial para a valorização dos cidadãos, visa a concretizar com uma política educativa que "pretende garantir a igualdade de oportunidades e promover 0 sucesso educativo de todos os alunos, ao longo dos 12 anos de escolaridade obrigatória." (DESPACHO n0 8476-A/2018).

No entanto, ao não considerar o esforço de autonomia de gestão de recursos por parte das escolas, essa proposta mostra-se contraditória em seus desígnios, visto que desconsidera que é no processo de organização interna que a escola possibilita processos de partilha e de responsabilização, favorecendo, em contrapartida, processos de autorregulação das aprendizagens dos seus integrantes e a conquista da cidadania (Santos et al, 2011).

As AE surgem, então, como fruto de uma política educativa que tem como centro as pessoas e que assume a aprendizagem como essencial para a promoção de valores e competências que possibilitem aos sujeitos lidarem com as transformações constantes na sociedade contemporânea. A aprendizagem, como centro do processo educativo e favorecedora da capacidade de saber, mostrase como um elemento constante em uma realidade sempre em mudança, sendo assumida como a base da formação ao longo da vida e da construção das competências. Estas, definidas como combinações complexas de conhecimentos, capacidades e atitudes (PERFIL, 2017, documento eletrônico; UNESCO, 2017), aparecem como o foco das AE em cada área/disciplina específica do currículo do ensino obrigatório.

Ademais, de acordo com o pressuposto curricular defendido, essa proposta retoma e concretiza a visão de Aprendizagens Essenciais preconizada pela OCDE, uma vez que as AE correspondem ao que deve/pode ser aprendido por todos (Roldão, Peralta, \& Martins, 2017, p.8), o que revela a face inclusiva do currículo e a ideia de que todos têm potencialidades para aprender. Rompe, então, com a noção do determinismo biológico e/ou social e assume a perspectiva de que não existe aprendizagem sem ensino, visto que o professor é tomado como ator responsável pelo processo educacional a partir das estratégias pedagógicas que realiza, realçando a mediação social no processo de desenvolvimento das competências almejadas e da autorregulação das aprendizagens. Desse modo, supera a concepção assumida pela UNESCO (2017) de que as competências não se ensinam, mas se desenvolvem durante a ação, com base na experiência e reflexão, pelo próprio aluno.

Orientadas e convergentes com o Perfil do Aluno, as AE propõem-se ao desenvolvimento pessoal e social dos sujeitos com vistas ao exercício da cidadania consciente, inclusiva e interventiva, com atenção às diferenças e contribuição para o desenvolvimento sustentável (UNESCO, 2017), no qual o processo criativo tem papel preponderante para lidar com as exigências das novidades que as questões globais impõem. Deste modo, as AE surgem na tentativa de responder aos anseios da Educação para o Desenvolvimento Sustentável (EDS) que tem como eixo central e transversal 0 Objetivo da Educação Sustentável, uma vez que a educação é tomada como estratégia essencial na busca pela concretização da EDS.

Assim, a proposta de política educacional de Portugal alinha-se à Agenda 2030 para 0 Desenvolvimento Sustentável à medida em que dialoga explicitamente com 0 Objetivo de Desenvolvimento Sustentável 4, a saber: "Educação de qualidade - Assegurar a educação inclusiva e equitativa de qualidade, e promover oportunidades de aprendizagem ao longo da vida para todos" (UNESCO, 2017, p.6). Isso com o propósito último de promover nos alunos dessa geração global novas maneiras de pensar e agir transpassadas pela ética para a sustentabilidade social, cultural, econômica e ambiental de Portugal e do mundo (PERFIL, 2017, documento eletrônico). Além disso, 


\section{O TRABALHO DO PROFESSOR E AS PRESCRIÇÕES DO DOMÍNIO DA LEITURA NAS AE EM PORTUGAL}

converge para a realização dos objetivos descritos no Quadro Europeu de Competências Essenciais para a Aprendizagem ao Longo da Vida (COMISSÃO EUROPEIA, 2007), o qual orienta no sentido de que os sistemas educacionais da União Europeia se organizem para promover o desenvolvimento de competências essenciais que assegurem aos aprendizes adaptar-se com flexibilidade às constantes mudanças sociais em um mundo interligado a partir da garantia da realização e desenvolvimento pessoais para o exercício de uma cidadania ativa, para a inclusão social e para 0 emprego.

E é nesse enquadramento que a reorganização curricular do ensino básico e secundário de Portugal, tendo o Perfil do Aluno como referência, prescreve, em consonância com as recomendações anteriores do CNE, a Educação para a Cidadania em uma dimensão tanto disciplinar como transdisciplinar "com vista ao exercício da cidadania ativa, de participação democrática, em contextos interculturais de partilha e colaboração e de confronto de ideias sobre matérias da atualidade" (DECRETO-LEI n. $.55 / 2018$ ), superando 0 modelo exclusivamente disciplinar e não integrado desse tema no currículo.

Além disso, assume que esse componente curricular deve ser implementado de maneira autônoma pela escola no diálogo com os alunos, a família e a comunidade para ser objetivado nas disciplinas/áreas específicas do currículo, na integração das suas diferentes áreas, dando voz aos diferentes atores da escola para promover o desenvolvimento de cidadãos comprometidos com um mundo mais justo e acolhedor para todos. Isso a exemplo das AE para a Língua Portuguesa que se concretizam na intersecção de diversas áreas do ensino e da aprendizagem, como é o caso das competências que promovem 0 conhecimento, as capacidades e as atitudes relativas à leitura no $2^{\circ}$ ano do $1^{0}$ Ciclo do Sistema de Ensino, foco dessa análise, e que estão comprometidas com uma literacia mais compreensiva, inclusiva e responsável para atuação dos sujeitos no mundo em intensa transformação (APRENDIZAGENS ESSENCIAIS.... 2 ANO, PORTUGUÊS, 2018, documento eletrônico).

\section{0 status da leitura nas Aprendizagens Essenciais - $2^{0}$ Ano, $1^{0}$ ciclo do Sistema de Ensino}

Em consonância com o Programa e Metas Curriculares de Português do Ensino Básico (Buescu, Morais, Rocha, \& Magalhães, 2015) ${ }^{3}$, as AE reafirmam a concepção de língua como funcionalidade, destacando-a como fator de inserção social, de desenvolvimento cognitivo e de constituição do sujeito estético.

Em termos de concepção de aprendizagem, pode-se inferir que as EA avançam no sentido de assumir esse fenômeno como algo que acontece como um movimentos de avanços e retrocessos, em progressão constante (Vigotski, 1991), já que admite que "Ao longo do 1.․ ciclo do ensino básico, a disciplina de Português permitirá aos alunos desenvolverem, em níveis progressivamente mais exigentes, competências nucleares em domínios específicos". Diferentemente do Programa e Metas (Buescu, Morais, Rocha, \& Magalhães, 2015) que "Define os conteúdos por ano de escolaridade e apresenta uma ordenação sequencial e hierárquica para os nove anos do Ensino Básico" (p. 3), sugerindo uma ordenação dos conteúdos em sequência e de maneira linear. Essa perspectiva é passível de interpretação mesmo quando afirma que os objetivos e metas indicados nas Metas Curriculares "são obrigatórios em cada ano de escolaridade e devem ser mobilizados em anos subsequentes sempre que necessário" (p.8), pois indica que 0 aprofundamento e a consolidação dos conteúdos ao longo do $1^{0}$ Ciclo do Ensino Básico não estão previstos como atividade constante de ensino que busca funcionar como apoio à aprendizagem.

As AE, assim como o Programa e Metas, fazem referência ao gênero de texto, ressaltando a importância da apropriação desse tipo de instrumento psicológico (Vigotski, 1991) para o "desen-

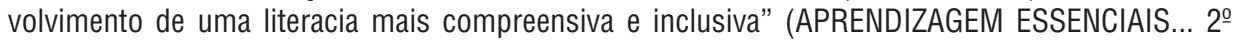


ANO, 1ํㅡ는, PORTUGUÊS, 2018, p. 2), porém, não há referência direta no documento quanto à definição desse conceito nem a menção de qual seria a unidade de ensino da Língua Portuguesa, em Portugal. No Programa e Metas afirma-se que é no 1ํㅡㄷㅣo do Ensino Básico que "tem início, ao nível da oralidade, a prática dos géneros escolares (Dolz e Schnewly, 1996, Coutinho, 2015, Pereira e Cardoso, 2013), que, posteriormente, se irá desenvolvendo, ao longo de todo o Ensino Básico e Secundário" (p. 7), porém, apesar de explicitamente fazer menção a pesquisadores da Didática da Língua, com afiliação ao ISD, não há no documento a distinção explícita entre gênero de texto e tipo de texto/tipo de discurso, bem como, às vezes, parece se eleger, contraditoriamente, a palavra como unidade de ensino da língua, como é observado na disposição dos conteúdos relativos ao $2^{\circ}$ ano desse ciclo no que se refere ao Domínio Leitura-Escrita:

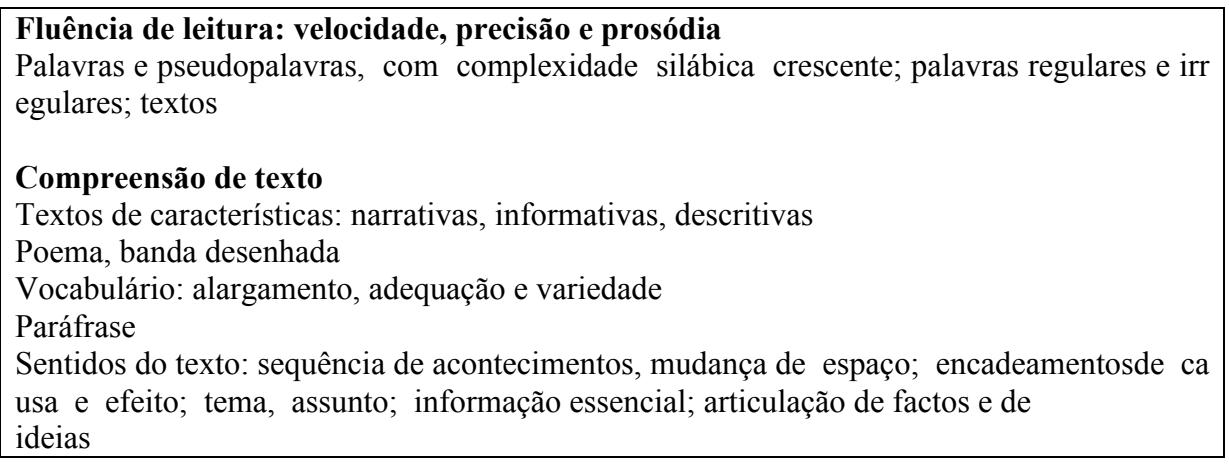

Fonte: Programa e Metas Curriculares de Português do Ensino Básico (2015, p.11)

Nesse caso, no tópico "Fluência de leitura", a orientação de ensino sugere o caminho da palavra para o texto, contrariando a proposta de integração dos domínios da língua na concretização de seu ensino e a compreensão sobre a sua funcionalidade (Marcuschi, 2008). Já no tópico da "Compreensão de texto", há a referência aos gêneros de textos que devem ser apropriados nesse ano escolar (poema e banda desenhada), mas sem relacioná-los ou diferenciá-los do tipo de texto/tipo de discurso mencionados (narrativas, informativas, descritivas) e que devem ser objeto de ensino.

Nas AE, embora se mencione a necessidade dos falantes participarem das situações de linguagem ativando uma "pluralidade de géneros textuais", não há referência ao ensino de gênero ao longo do $1^{0}$ Ciclo, além disso, na sistematização da "Operacionalização das Aprendizagens Essenciais (AE)", no âmbito dos "Conhecimentos, Capacidade e Atitudes" referentes ao Domínio da LeituraEscrita, especificamente à competência textual, há opção de se fazer referência ao tipo de texto/tipo de discurso e as suas finalidades: "Compreender o sentido de textos com características narrativas e descritivas, associados a finalidades diferentes (lúdicas, estéticas, informativas)", fazendo-se inferir sobre uma não afiliação à perspectiva do gênero de texto como constitutivo do ensino da língua (Schneuwly \& Cordeiro, 2016).

Nos dois documentos, há a ênfase do ensino e aprendizagem da língua a partir da intersecção dos seus diferentes domínios (oralidade, escrita, leitura, educação literária e gramática), porém, nas AE faz-se menção ao domínio da Educação Literária como o lugar propício dessa integração porque se compreende que "sendo objeto o texto literário, nele se refletem procedimentos de compreensão, análise, inferência, escrita e usos específicos da língua" (APRENDIZAGENS ESSENCIAIS, ํㅜㅡㄴ 


\section{O TRABALHO DO PROFESSOR E AS PRESCRIÇÕES DO DOMÍNIO DA LEITURA NAS AE EM PORTUGAL}

ANO, 1ํㅡ는 PORTUGUÊS, 2018, p. 3). Assim, de maneira coerente com esse pressuposto, há como orientação ao professor a indicação de promoção de estratégias de mobilização de conhecimento sobre a língua e sobre o mundo para a interpretação de "expressões e segmentos" de narrativas literárias. Porém, novamente, existe a ênfase na parte e não no todo do texto para a compreensão da sua composição e estilo por meio do recurso da língua e, inversamente, para a compreensão da língua através das características do gênero de texto.

Além disso, em ambos os documentos, $01^{0}$ e $02^{\circ}$ anos do $1^{0}$ Ciclo estão estruturados em quatro e não em cinco domínios como nos demais anos do ensino básico, a saber: oralidade, leituraescrita, educação literária e gramática. Portanto, nos dois primeiros anos desse ciclo, a leitura e a escrita aparecem como um único domínio, porque se entende que embora "Sendo funções distintas, elas apoiam-se em capacidades que Ihes são em grande medida comuns" (Buescu, Morais, Rocha, \& Magalhães, 2015, p. 7). Esse pressuposto é reafirmado no caderno de apoio "Aprendizagem da leitura e escrita", parte integrante do Programa e Metas (2015), ao afirmar que esses domínios se influenciam reciprocamente porque "Aprender a escrever é um dos melhores meios de aprender a ler e reciprocamente... Na verdade, a escrita consolida a representação dos fonogramas que intervêm na decodificação das palavras" (METAS, 2015, p. 3).

Percebe-se, então, a concepção de leitura sustentada notadamente na decodificação, sendo a palavra a unidade do ensino e da aprendizagem dessa atividade humana. Além disso, mesmo assumindo que, no $1^{\circ}$ ano e parcialmente ainda no $2^{\circ}$ ano, a leitura de textos realizada pelo professor não se configure como um monólogo, mas como "uma atividade de interação sistemática com as crianças" (METAS, 2015, p. 3), a leitura mostra-se como um meio para aumentar o vocabulário, para trabalhar a oralidade, para explicar a gramática e mesmo para verificar a compreensão, mas sem se realçar as estratégias de interação do leitor com o texto que podem ser aprendidas nas rodas de leitura, tendo-se o professor como um modelo de leitor maduro e desenvolvido (Oliveira, 2007; Oliveira \& Ferreira, no prelo).

Deste modo, fundamentado e coerente com a perspectiva da psicolinguística cognitiva experimental e das neurociências cognitivas, o caderno de apoio "Aprendizagem da leitura e escrita" sustenta que 0 desenvolvimento da decodificação precisa acontecer antes do ensino da compreensão, sendo esta última concebida como "extração da informação ou do sentido" daquilo que o autor quer dizer, "o que faz da fidelidade à intenção do autor o principal critério da compreensão do texto" porque "0 aluno deve aprender a respeitar o texto" (METAS, 2015, p.11). Admite, portanto, que aprender a compreender um texto implica aprender a responder "a algumas questões dominantes, como, por exemplo, 'de que trata o texto' (o tema), 'o que é que ele nos diz' (o assunto)" (p.13), afirmando que as respostas a essas perguntas podem ser sugeridas no início do texto ou confirmadas ou ajustadas ao longo da leitura. Assim, não considera a participação ativa e respondente do leitor na sua interação com o texto (Bakhtin, 2003), fazendo-se inferir que o documento adota a concepção de texto como produto acabado, como um container em que se busca coisas (Marcuschi, 2008), e não como processo em constante reelaboração pelos leitores.

Ademais, partindo das abordagens teóricas adotadas, considera a aprendizagem da leitura e da escrita como um processo cognitivo complexo, porém, contraditoriamente, realça os processos cognitivos da atenção e da memória de trabalho, em detrimento dos processos inferenciais e de monitoramento da compreensão, que juntamente com a memória de trabalho são assumidos como processos cognitivos superiores envolvidos na leitura. Assim, embora faça referência à importância do conhecimento do leitor sobre o tema do texto lido, sobre os gêneros de texto e sobre as relações entre informações textuais e conhecimento prévio do leitor, não se discutem as estratégias de mediação docente para alcançar "Um dos objetivos mais importantes do ensino da compreensão 
[que] é permitir ao aluno a autorregulação" (METAS, 2015, p. 14), já que se entende que "o que pode tornar difícil o progresso em compreensão não é tanto a dificuldade de aquisição de estratégias quanto as possíveis insuficiências das capacidades cognitivas e linguísticas que estão na base dos conhecimentos utilizados nas estratégias." (p. 14).

Desse modo, como há a compreensão de que o desenvolvimento da decodificação deve acontecer necessariamente antes do ensino e aprendizagem da compreensão textual, parece ser admitido que, ao realizar a atividade de compreensão, o aluno já teria certa autonomia, não havendo aqui a ênfase na aprendizagem pela mediação de um outro (o professor, por exemplo) como fundamental para o desenvolvimento do sujeito (Vigotski, 1991), neste caso, o desenvolvimento do leitor crítico e compreensivo.

Contrariamente, no que se refere às $A E$, afirma-se que ao longo dos $1^{\circ}$ e $2^{0}$ anos do $1^{\circ}$ ciclo da Escola Básica, pretende-se desenvolver a "competência da leitura com vista a um domínio progressivamente mais seguro da compreensão dos textos", bem como desenvolver "educação literária por meio de uma relação afetiva e estética com a literatura e com textos literários orais e escritos" (APRENDIZAGENS ESSENCIAIS, 2ํANO, 1ำ CICLO, PORTUGUÊS, 2018, p. 4). Nesse caso, evidencia-se a ênfase no desenvolvimento da capacidade de compreensão alcançada pelas estratégias de ensino promovidas no âmbito do domínio de leitura-escrita, bem como o desenvolvimento da competência afetivo-estética a partir da experimentação artístico-literária alcançada pela mediação com a literatura portuguesa e estrangeira.

Assim, quando se destaca a compreensão de textos narrativos e descritivos, as estratégias de ensino sugeridas para garantir o desenvolvimento do leitor, envolve sete de dez descritores do perfil do aluno (Leitor - descritores: A, B, C, D, F, H, I ${ }^{4}$ ), as quais demonstram a complexidade dessa atividade humana, que envolve desde 0 conhecimento de diferentes linguagens, passando pela capacidades cognitivas, até o desenvolvimento de capacidades subjetivas e estéticas. Portanto, nesse caso, são explicitadas como estratégias, a mobilização de experiências e saberes (de mundo do aluno), localização de palavras e informações explícitas no texto para a produção de sentidos, inferências com base em informações explícitas, monitoramento da compreensão, auxílio à web (como recurso de ajuda e orientação, além do professor, que contribui para a autonomia do alunoleitor) e aquisição de saberes relacionadas à organização textual.

Em complementariedade a essas ações estratégicas para promover 0 desenvolvimento do aluno-leitor crítico e ativo, no domínio da "Educação Literária" são descritas ações estratégicas de ensino referentes ao "questionar aspetos da narrativa" e ao "exprimir reações subjetivas de leitor". No entanto, aqui percebe-se, implicitamente, a noção de que apenas na interação com o texto literário, mais polissêmico, o leitor teria mais liberdade de expressão emocional-subjetiva e de questionamento ao autor. No entanto, quando se assume a perspectiva de leitura como polissêmica e do leitor como sujeito ativo, espera-se que essas operações de linguagem aconteçam na interação do leitor com 0 autor de qualquer gênero textual e precisam ser ensinas de maneira intencional (Machado, 2009).

Também nas ações estratégias de ensino presentes no domínio da educação literária, verificamse aquelas que privilegiam o desenvolvimento do percurso individual do aluno-leitor na seleção de obras para além daquelas selecionadas e indicadas nas $\mathrm{AE}$, em parceria com a biblioteca escolar, por exemplo. Isso com o objetivo de "Fazer da leitura um gosto e um hábito para a vida e encontrar nos livros motivação para ler e continuar a aprender [...] a partir de recursos e estratégias diversificados, que o Plano Nacional de Leitura (PNL, 2017) disponibiliza".

Assim, em consonância com o caderno de apoio "Aprendizagem da leitura e da escrita" e com o próprio PNL, as AE defendem que a promoção da leitura e a formação do aluno-leitor não se limi- 


\section{O TRABALHO DO PROFESSOR E AS PRESCRIÇÕES DO DOMÍNIO DA LEITURA NAS AE EM PORTUGAL}

ta à sala de aula, mas se concretiza na relação entre esse micro contexto social e outros setores ou atividades existentes na sociedade, como é o caso da família, das bibliotecas escolares e públicas, e associações diversas. Além disso, compreende-se que ao ressaltar esse tipo de parceria, assim como a PNL, as AE sustentam-se na noção de que o desenvolvimento da leitura acontece de maneira dialogada e na relação com modelos de leitor maduro, capazes de mediar a relação do leitor iniciante com 0 autor do texto.

Ainda, percebe-se que há no domínio da educação literária a ênfase na formação de um leitor independente e em formação contínua e progressiva, fazendo aludir à concepção de leitura como uma capacidade que se complexifica ao longo da vida e que não está pronta e acabada quando se aprende a decodificar (Ferreira, Lima, \& Gonçalves, 2011; Gonçalves \& Souza, 2010). Também sugere que 0 desenvolvimento do leitor não se restringe à sala de aula do professor de português, visto que os textos das diferentes disciplinas apresentam organização específica que exigem formas distintas de serem lidos (Carvalho \& Souza, 2012) e que precisam ser ensinadas e aprendidas a partir da mediação docente enquanto trabalho coletivo (Amigues, 2004) desenvolvido com os alunos em sala de aula, e na troca com outros autores escolares e extraescolares.

\section{CONSIDERAÇÕES FINAIS}

Na busca de se refletir sobre as prescrições do ensino e aprendizagem da leitura materializadas nas Aprendizagens Essenciais (AE) referentes ao 2ํㅡㄹ Ano do $1^{0}$ Ciclo do Sistema de Ensino de Portugal, a partir de uma análise que contempla as determinações sócio históricas marcadas pelos movimentos de oposição, concordância, simetrias e assimetrias e que lança luz sobre a gênese das mudanças, percebe-se que as AE nascem em um contexto que se pretende dialogal, dialógico e coletivo, assumindo o professor como um dos interlocutores no processo de sua produção. No entanto, essa participação mostra-se restrita porque acontece em forma de representação por associações de classe. Além disso, a coautoria mostra-se apagada quando do produto final, que emerge possivelmente como um Guia de Orientações Pedagógicas porque pretende mais orientar do que prescrever.

As AE também nascem em contexto de tensão acerca das discussões sobre a extensão e a flexibilidade curriculares. Esta última em discussão desde os anos 80 do século XX, em Portugal (Formosinho \& Machado, 2008) e, ainda, não esgotada e superada com a nova reorganização curricular do ensino básico e secundário materializada nas $A E$, homologada pelo Despacho $n^{0} 8476$ A/2018, em consonância com outros dispositivos legais. Além disso, as AE tem origem em um momento histórico em que se exigem sujeitos capazes de lidar com uma sociedade complexa, diversa e em mudança constante, que impõe às instituições sociais, a exemplo da escola, uma intervenção em uma perspectiva inclusive e de promoção dos valores éticos e estéticos, em que as linguagens têm lugar relevante para favorecer a comunicação e, em especial, a compreensão críticas das informações que abundantemente circulam em diferentes contextos e mídias.Portanto, as AE são tecidas a partir de uma perspectiva inclusiva, interdisciplinar e voltada à autonomia das escolas e dos professores, mas ainda esbarra em questões de gestão financeira, de tempo e de organização do trabalho escolar coletivo que tenha apoio em um suporte organizacional (Formosinho \& Machado, 2008 ) para implementação e materialização dessas ideias que também fazem parte do enquadramento dos documentos internacionais e da União Europeia.

Em termos do status da leitura evidenciado nas AE para promover a formação do sujeito-leitor, percebe que ela avança em relação ao Programa e Métodos no que se refere à ênfase na compreensão textual e na formação de um leitor independente, que progride continuamente e de maneira cada vez mais complexa, tendo o livro/texto como recurso principal de aprendizagens diversas, 
ao longo da vida, especialmente, no que diz respeito às ações estratégicas de ensino no domínio da Educação Literária.

Por outro lado, as AE ainda demonstram contradições quanto ao ensino e aprendizagem da leitura, notadamente, (i) sobre a eleição da unidade de ensino da língua, ora ressaltando o gênero de texto ora realçando a palavra; e (ii) sobre a ação ativa do leitor na relação com o autor do texto, uma vez que mesmo contemplando a produção de sentidos no domínio da leitura-escrita, é no domínio da educação literária que o posicionamento responsivo (Bakhtin, 2003) do leitor é levado em consideração, fazendo suspeitar que esse tipo de ação deve ser considerada apenas na relação do leitor com os textos literários, fazendo emergir, mesmo que implicitamente, a antiga discussão entre arte e ciência ou entre a subjetividade e a objetividade dos textos literários e científicos/escolares, respectivamente, e consequentemente, sobre a autoridade do autor no processo de compreensão textual.

Em vista do exposto, sugere-se a realização de investigações que possam acompanhar a ação dos professore em sala de aula voltadas para a formação do aluno-leitor do 1ํㅡㄹ Ciclo da Escola Básica, em Portugal, a partir da implementação das AE, que será progressivamente implementada, a começar pelo $1^{\circ}$ ano do $1^{\circ}$ Ciclo, desde 0 ano letivo 2018-2019. Propõe-se, ainda, que essas investigações contemplem o engajamento dos alunos nas aulas de Português nos domínios da leituraescrita e de educação literária em uma perspectiva coletiva do trabalho docente na interlocução com os alunos em sala de aula, visando às ações realizadas e possíveis do professor como constitutivas desse trabalho.

\section{REFERÊNCIAS}

Amigues, René (2004). Trabalho do professor e trabalho de ensino. In A. R. Machado (Org.), 0 ensino como trabalho: uma abordagem discursiva (pp. 35-53). Londrina: Eduel.

Aprendizagens essenciais. Direção-Geral da Educação. República Portuguesa, 2018. Recuperado de http://www.dge.mec.pt/aprendizagens-essenciais.

Aprendizagens essenciais-articulação com o perfil dos alunos. Português. $2^{\circ}$ Ano $1^{\circ}$ Ciclo, Ensino Básico. República Portuguesa, 2018. Recuperado de http://www.dge.mec.pt/sites/default/files/Curriculo/Aprendizagens_Essenciais/10_portugues.pd f

Bakhtin, M. (2003). Estética da criação verbal (4a ed.). São Paulo: Martins Fonte.

Bronckart, J. P. (2006). Atividade de linguagem, discurso e desenvolvimento humano. (Org. A. R. Machado, M. L. M. Matencio. Trad. Anna Rachel Machado, Maria Ângela Paulino Teixeira Lopes, Maria de Lourdes Meirelles Matencio, Rosalvo Gonçalves Pinto). Campinas: Mercado de Letras (Obra original publicada em 2004).

Buescu, H. C., Morais, J.; Rocha, M. R. \& Magalhães, V. F. (2015) Programa e metas curriculares de português do ensino básico. Ministério da Educação e Ciência, Portugal.

Carvalho, C. \& Souza, 0. C. (2012). Portugal e Brasil: Letramento e ensino de leitura. Polifonia. Cuiabá, MT, v. 19, n 25. P. 181-196, jan/jul.

Comissão Europeia. Competências essenciais para a aprendizagem ao longo da vida quadro de referência Europeu. Luxemburgo: Serviço das Publicações Oficiais das Comunidades Europeias, 2007. Recuperado de http://ec.europa.eu/dgs/education_culture/publ/pdf/ll-learning/keycomp_pt.pdf

Decreto-Lei n. 55/2018, de 06 de julho de 2018. Estabelece 0 currículo dos ensinos básico e secundário, os princípios orientadores da sua conceção, operacionalização e avaliação das aprendizagens. Recuperado de https://dre.pt/application/conteudo/115652962 


\section{O TRABALHO DO PROFESSOR E AS PRESCRIÇÕES DO DOMÍNIO DA LEITURA NAS AE EM PORTUGAL}

Despacho n. 8476-A/2018, de 31 de agosto de 2018. As Aprendizagens Essenciais das disciplinas dos cursos científico - humanísticos de Ciências e Tecnologias, Ciências Socioeconómicas, Línguas e Humanidades e Artes Visuais. Recuperado de https://dre.pt/application/conteu$\underline{\mathrm{d} 0 / 116279697}$

Ferreira, S. P., A. Lima, M. P., T. N.; Gonçalves, F. M. da S. (2011). A interlocução entre aluno-leitor/autor em sala de aula e a mediação do docente universitário. Psicologia: Teoria e Prática, 13(1), 62-74.

Suárez, N. \& Jiménez, J. E. (2014) ¿Influyen los años de experiencia y la especialidad de los profesores en las teorías implícitas que se atribuyen sobre el aprendizaje de la lectura? International Journal of Developmental and Educational Psychology INFAD Revista de Psicología, 1(2), 257262.

Formosinho, J. \& Machado, J. (2008). Currículo e organização: as equipas educativas como modelo de organização pedagógica. Currículo sem Fronteiras, 8(1), 5-16.

Friedrich, J. (2012). Lev Vygotski: médiation, apprentissage et développement - une lecture philosophique et épistémologique (2a ed.) (Collection Carnets des sciences de l'éducation). Université de Génève, Faculté de Psychologie et des Sciences de l'Éducation: Genève.

Gonçalves, C. \& Souza, 0. C. (2010). Português Le/L1: compreensão na leitura. Limite, 4, 119-139. Machado, Ana R. (1998). O diário de leituras: a introdução de um novo instrumento na escola. São Paulo: Martins Fontes.

Machado, A. R. (2009). Diários de leituras a construção de diferentes diálogos na sala de aula. In L. S. Abreu-Tardelli, \& V. L. L. Cristovão (Orgs.). Linguagem e Educação o ensino e a aprendizagem de gêneros textuais (pp. 71-91). Campinas: Mercado das Letras.

Marcuschi, L. A. (2008). Produção textual, análise de gêneros e compreensão. São Paulo: Parábola Editorial.

Metas Curriculares de Português. Caderno de Apoio - Aprendizagem da Leitura e da Escrita (LE). Direção Geral da Educação. Ministério da Educação, Portugal, 2015. Recuperado de: http://www.dge.mec.pt/sites/default/files/Basico/Metas/Portugues/caderno_aprendizagem_da_I eitura.pdf

Oliveira, K. R. S. (2017). Compreensão de textos literários na educação infantil: rodas de leitura e mediação docente (Dissertação de mestrado). Universidade Federal de Pernambuco - Programa de Pós-graduação em Psicologia Cognitiva, Recife, PE, Brasil.

Oliveira, K. R. S. \& Ferreira, S. P. A. (no prelo). Compreensão de textos literários por alunos da educação infantil. Psicologia Escolar e Educacional.

Parecer CNE/Portugal n. 11, de 28 de maio de 2018. Dispõe sobre o Currículo dos ensinos básicos e secundário. Recuperado de https://dre.pt/application/conteudo/115392237

Parecer Conselho das Escolas/Portugal n 04, de 14 de maio de 2018. Dispõe sobre o Currículo dos ensinos básicos e secundário. Recuperado de http://www.cescolas.pt/wpcontent/uploads/2018/05/Parecer_04_2018_Revisao_Curricular.pdf

Perfil dos alunos à saída da escolaridade obrigatória. Ministério da Educação. Direção-Geral da Educação. República $\quad$ Portuguesa, $2017 . \quad$ Recuperado de https://dge.mec.pt/sites/default/files/Curriculo/Projeto_Autonomia_e_Flexibilidade/perfil_dos_a lunos.pdf..

Plano Nacional de Leitura. 2017. Recuperado de http://www.pnl2027.gov.pt.

Roldão, M. C.; Peralta, H.; Martins, I. P. (2017). Currículo do ensino básico e do ensino secundário para a construção de aprendizagens essenciais baseadas no perfil dos alunos. Recuperado de http://www.dge.mec.pt/sites/default/files/Curriculo/Projeto_Autonomia_e_Flexibilidade/ae_docu 
mento enquadrador.pdf. Acesso em: 07 de out. de 2018.

Santos, M. E. B., Marques, A., Cibele, C., Matos, F., Menezes, I., Nunes, L., Paulus, P., Nobre, P., \& Fonseca, T. (2011) Educação para a cidadania - Proposta Curricular para os Ensinos Básico e Secundário. Disponível em: https://www.dge.mec.pt/sites/default/files/ECidadania/ed cidadania basico sec 2011.pdf. Acesso em: 07 de out.2018.

Schneuwly, B. \& Cordeiro, G.S. (2016). Le genre de texte comme objet autonome d'enseignement: comparaison de deux approches didactiques. In Cordeiro, G. S. \& Vrydaghs, D. (Orgs.). Statuts des genres en didactique du français. (pp. 83-107). Namur: Presses universitaires de Namur.

Unesco. Educação para os Objetivos de Desenvolvimento Sustentável - Objetivos de aprendizagem., 2017. Recuperado de https://nacoesunidas.org/wp-content/uploads/2015/10/agenda2030-ptbr.pdf

Vygotski, L. S. (1991). A formação social da mente (4a ed.). São Paulo: Martins Fontes.

Vigotski, L. S. (2004). Sobre 0 artigo de K. Koffka. "A introspecção e o método da psicologia." A título de introdução. In L.S. Vigotski, Psicologia teoria e método (pp. 87-92). São Paulo: Martins Fontes (Obra original publicada 1926).

1 As AE de Cada Nível de Ensino/Ciclo são identificadas por uma cor específica de modo a estabelecer uma identidade própria para cada etapa de ensino.

2 Para saber mais, consultar, por exemplo: Decretos-Lei $n^{0} 139 / 2012$, Decreto-Lei $n^{0} 54 / 2018$, Decreto-Lei n055/2018, Despacho n ${ }^{0}$ 5908/2017.

3 Este Programa, homologado em 2015, retoma as Metas Curriculares de Português do Ensino Básico homologadas em 2012 (Despacho n.- 5306/2012), para harmonizá-las em um único documento.

4 A: Linguagens e texto; B: Informação e comunicação; C: Raciocínio e resolução de problemas; D: Pensamento crítico e pensamento criativo; F: Desenvolvimento pessoal e autonomia; $\mathrm{H}$ : sensibilidade estética e artística; I: Conhecimento científico, técnico e tecnológico. 
